\title{
ULCER AND \\ NON-ULCER \\ DYSPEPSIAS
}




\section{PRACTICAL CLINICAL MEDICINE}

Series Editors J. Fry and G. Sandler
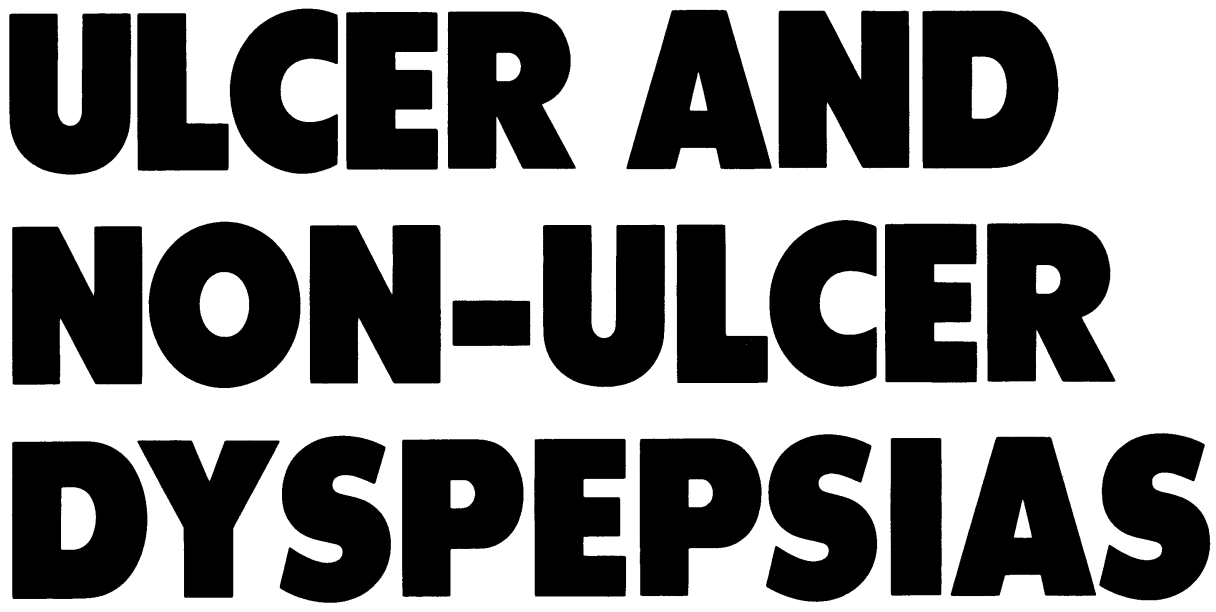

\section{Edified by}

M. Lancaster-Smith

Consultant Gastroenterologist

Queen Mary's Hospital

WKAP ARCHIEF

Sidcup

Kent 
Published in the UK and Europe by MTP Press Limited

Falcon House

Lancaster, England

British Library Cataloguing in Publication Data

Ulcer and non-ulcer dyspepsias.- (Practical clinical medicine)

1. Peptic ulcer

I. Lancaster-Smith, Michael II. Series 616.3'43 RC821

ISBN-13: $978-0-85200-691-7$ e-ISBN-13: 978-94-010-9928-8
DOI: $10.1007 / 978-94-010-9928-8$

Published in the USA by

MTP Press

A division of Kluwer Academic Publishers

101 Philip Drive

Norwell, MA 02061, USA

Library of Congress Cataloging in Publication Data

Ulcer and non-ulcer dyspepsias.

(Practical clinical medicine)

Includes bibliographies and index.

1. Peptic ulcer. 2. Dyspepsia.

I. Lancaster-Smith, Michael II. Series

[DNLM: 1 Dispepsia-physiopathology. 2. Peptic

Ulcer-physiopathology. WI 350 U36]

RC821.U43 $1986 \quad 616.3^{\prime} 43 \quad 86-27521$

ISBN-13: 978-0-85200-691-7

Copyright (C) 1987 MTP Press Limited

Softcover reprint of the hardcover 1st edition 1987

All rights reserved. No part of this publication may be reproduced, stored in a retrieval system, or transmitted in any form or by any means, electronic, mechanical, photocopying, recording or otherwise, without prior permission from the publishers. 


\section{Contents}

List of Contributors

vi

Series Editors' Foreword

vii

Introduction

ix

M. Lancaster-Smith

1 Pathophysiology of Peptic Ulcer

M. Hobsley and P. F. Whitfield

2 Oesophagitis

A.J.M. Watson and M.J.G. Farthing

3 Peptic Ulcer

M. Lancaster-Smith

4 Non-ulcer Dyspepsia

J.G.C. Kingham

Index 


\section{List of Contributors}

Dr M. J. G. Farthing

Senior Lecturer

Department of

Gastroenterology

St Bartholomew's Hospital

London EC1A 7BE

Prof M. Hobsley

The Middlesex Hospital

London W1N 8AA

Dr J. G. C. Kingham

Consultant Physician

Morriston Hospital

Swansea, Wales
Dr M. Lancaster-Smith

Consultant

Gastroenterologist

Queen Mary's Hospital

Sidcup, Kent

Dr A. J. M. Watson

Research Fellow

Department of

Gastroenterology

St Bartholomew's Hospital

London EC1A 7BE

Dr P.F. Whitfield

The Middlesex Hospital

London W1N 8AA 


\section{Series Editors' Foreword}

Backing up the pioneering medical researchers and experimenters are the phalanxes and cohorts of practising clinicians in district general hospitals and in general practice who may have to implement and apply any breakthroughs and advances in practical and realistic terms. This they cannot, and should not, be expected to do without careful consideration and analysis. It is essential, therefore, to have regular reviews of the growing points of medicine which are constructively critical as well as being enthusiastic and which can present the issues and implications clearly and fairly to clinicians.

The Practical Clinical Medicine series is designed to provide such regular reviews on selected subjects. Each volume is under the charge of an invited editor who selects his team of 4-6 experts. Each contribution is an authoritative, detailed and referenced examination of his topic, is clearly presented in an understandable manner and is practical, relevant and applicable to everyday clinical practice.

The series is intended as a means of communication between researchers and practising clinicians. It is dedicated to generalists who provide primary health care in general practice and to generalists providing secondary medical care in district 
general hospitals. Both are involved in applying good general practical clinical medicine for their patients, but can only succeed in a climate of constant review and examination.

JOHN FRY Gerald SANDLER 


\section{Introduction}

The disorders discussed in this volume are undoubtedly amongst the commonest reasons for seeking medical opinion and advice. Peptic inflammation and ulceration of the oesophagus, stomach and duodenum constitute approximately $50 \%$ of referrals from general practitioners to hospital gastroenterology clinics in the United Kingdom. In addition nonulcer dyspepsia in which category it is now customary to include the irritable bowel syndrome account for a further $40 \%$ of referred patients.

The epidemiological profile of peptic ulcer has changed significantly during this century and re-evaluation of this information may hopefully provide clues to the aetiology of gastric and duodenal ulceration. Furthermore during the past decade technological advances have encouraged vigorous research into the pathophysiological mechanisms involved in gastrooesophageal reflux, peptic ulcer and non-ulcer dyspepsia.

The advent of highly effective drugs that heal peptic lesions and the coincident burgeoning of upper gastrointestinal endoscopy have stimulated numerous long-term studies of these disorders. Their behaviour is now clearly understood and their recurrent nature has been unequivocally confirmed. The 
widespread use of endoscopy has shown that many patients with symptoms suggestive of peptic disease have no mucosal abnormality in the upper gastrointestinal tract. Rather it seems that many of them have functional disturbances of the small or large intestine which are now being more accurately defined.

Surgery for all forms of peptic disease has declined during the past decade but this trend is perhaps reversing in duodenal ulcer management due to the generally favourable result that the majority of patients experience after proximal gastric vagotomy.

It is not the intention of this book to comprehensively cover the total field of peptic disease and non-ulcer dyspepsias but rather to review those areas and topics which are likely to be of special interest to general practitioners.

M. LANCASTER-SMITH 